\title{
RELOCATING SCIENCE
}

Countries are spending more than ever on research and development, but the fields they fund vary depending on national priorities. And it is not just the research reputation that matters when choosing whether to move abroad - cost of living and quality-of-life are factors too.

\section{HOW SCIENCE IS SPREAD}

There is no doubt of China's dominance when it comes to publishing research in high-quality journals. Its weighted fractional count (WFC; a score used by the Nature Index, see description below) was 5\% higher in May 2015 to April 2016 compared with 2014. With the exception of New Zealand, the WFC of the other Asia-Pacific countries profiled fell.

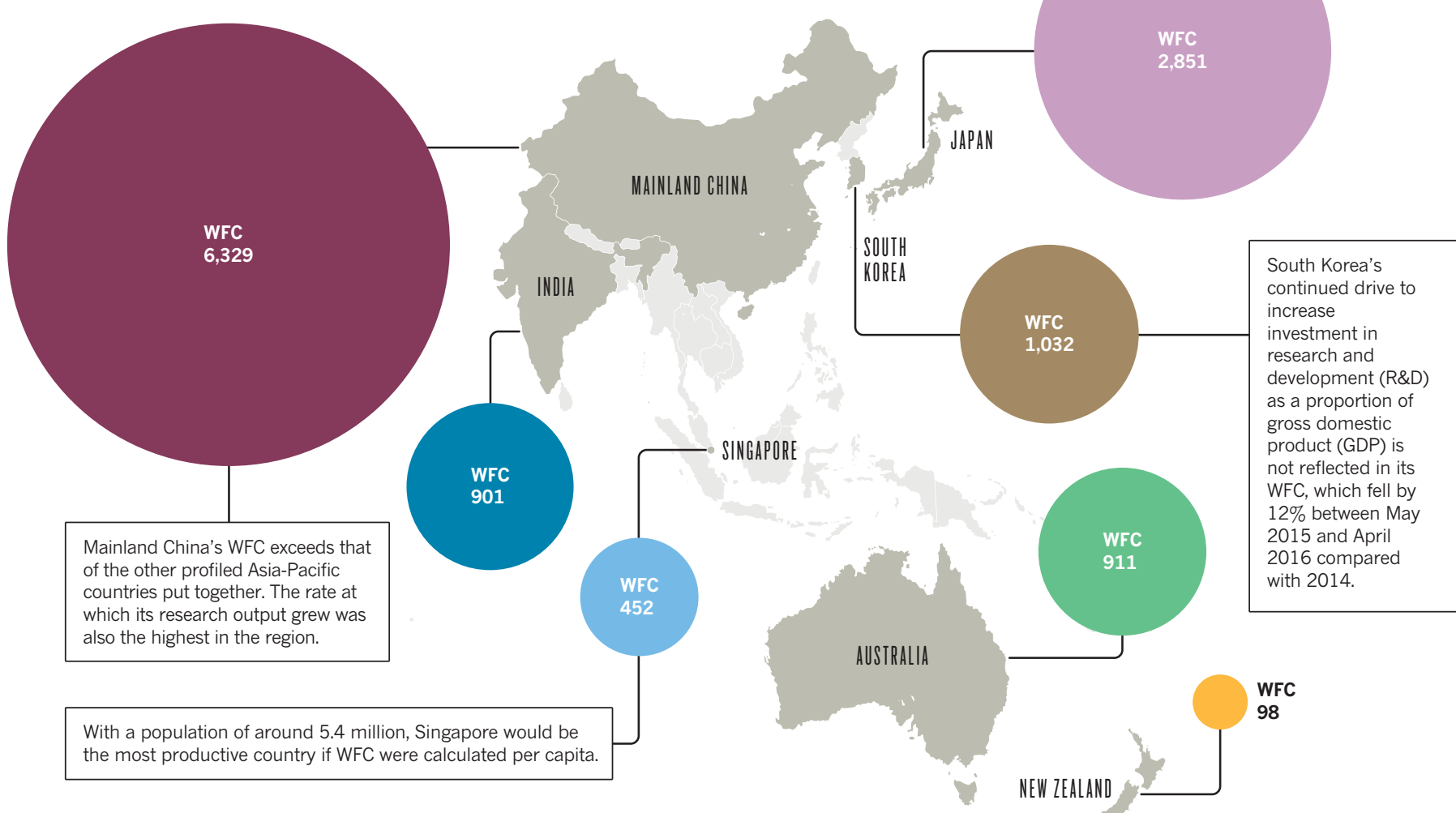

\section{SUBJECT STRENGTHS}

China devoted more of its research efforts to physics and less to health and medical sciences in 2015 than any of the other countries profiled, according to the number of academic journal articles in the Scopus database. Articles on boundaries between subjects can be counted more than once, potentially distorting the relative subject proportions in these charts.

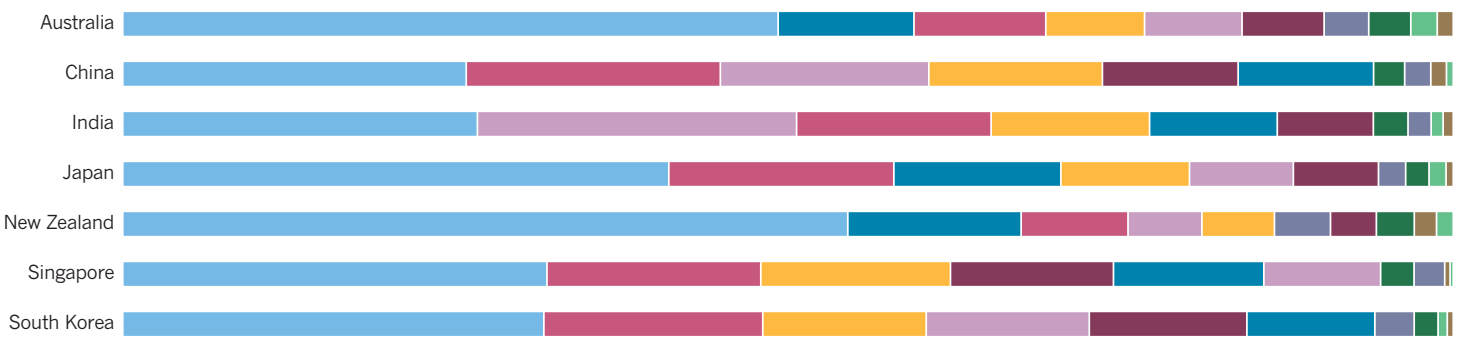

KEY

Astronomy
Biochemistry, molecular
biology and genetics
Chemistry
Earth sciences
Environmental
sciences and energy
Health and medical
sciences
Materials science
Mathematics, computer
science and engineering
Microbiology and
immunology
Physics

NATURE The Nature Index database tracks the affiliations of high-quality scientific articles, and charts publication productivity for institutions and countries. Weighted fractional count (WFC) INDEX accounts for the relative contribution of each author to an article and applies a weighting to correct imbalances in the index's subject coverage. This Career Guide draws on Nature Index data derived from articles published between 1 May 2015 and 30 April 2016. WFC is used throughout this supplement as the primary metric, because it provides an even basis for comparison. For more information, visit natureindex.com/faq 


\section{FUNDING OVER TIME}

R\&D funding as a proportion of GDP has grown most rapidly in South Korea and China since 2000, but has remained consistently low in India and New Zealand.

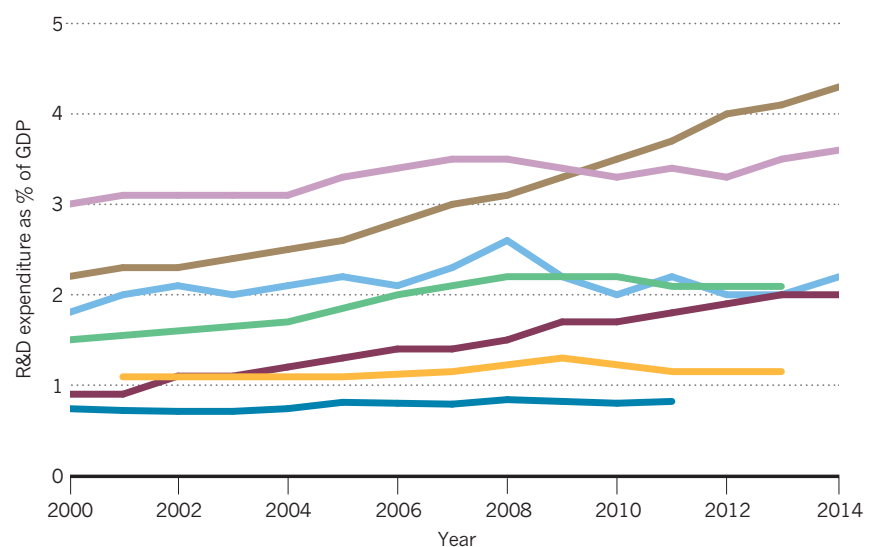

\section{RESEARCH QUALITY}

Singapore comes out on top for national research quality. Quality is based on the percentage of each country's biological and physical science articles in the Scopus database that make it into the Nature Index.

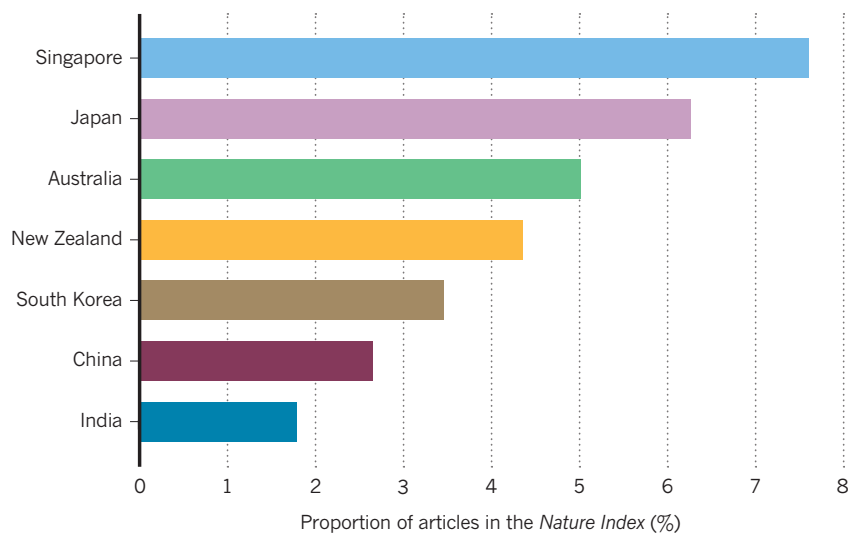

\section{COST OF LIVING}

Major cities in Australia are the most expensive places to live among the countries profiled, on the basis of an index of the relative ability of people on average salaries to buy goods and services.

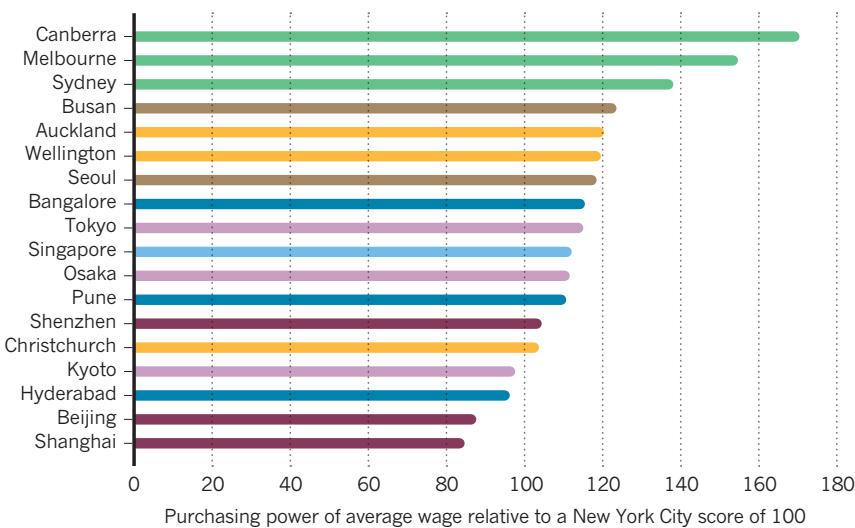

\section{SPENDING PER RESEARCHER}

Of the profiled countries, Singapore spends the most on R\&D per researcher. Figures are the most recent available and are normalized for purchasing power. The United States and United Kingdom are included for comparison.

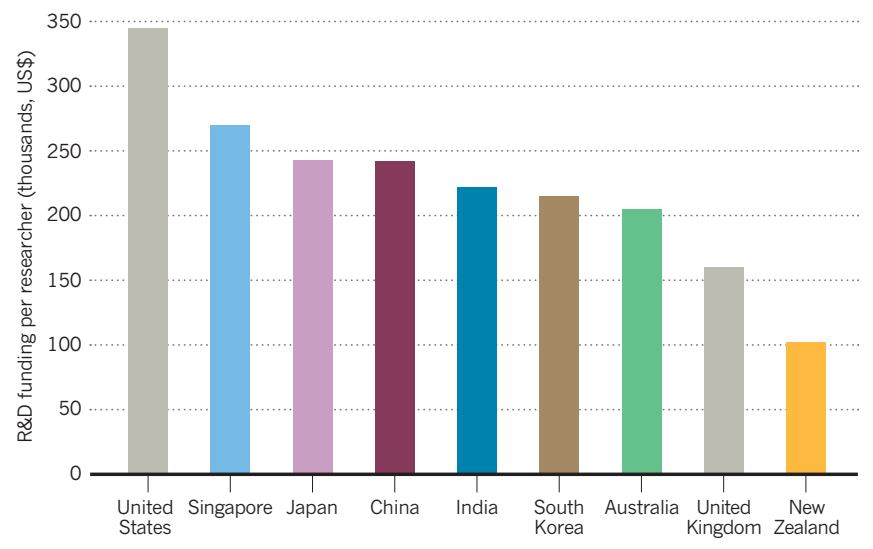

\section{RESEARCHER DENSITY}

South Korea has more of its workforce engaged in research than any of the other profiled countries. As a proportion of the working population, South Korea has around 30 times more researchers than India, according to the latest data available.

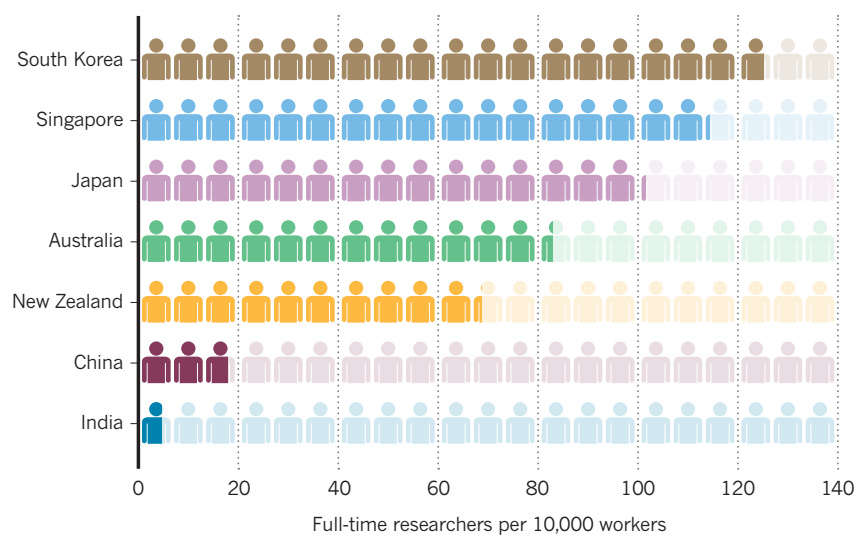

\section{LIFE SATISFACTION}

When people of 157 countries were asked to rate life satisfaction on a scale of zero to ten, New Zealanders and Australians were the happiest people of the seven profiled countries. Denmark (the happiest) and Burundi (the least happy) are included for comparison.

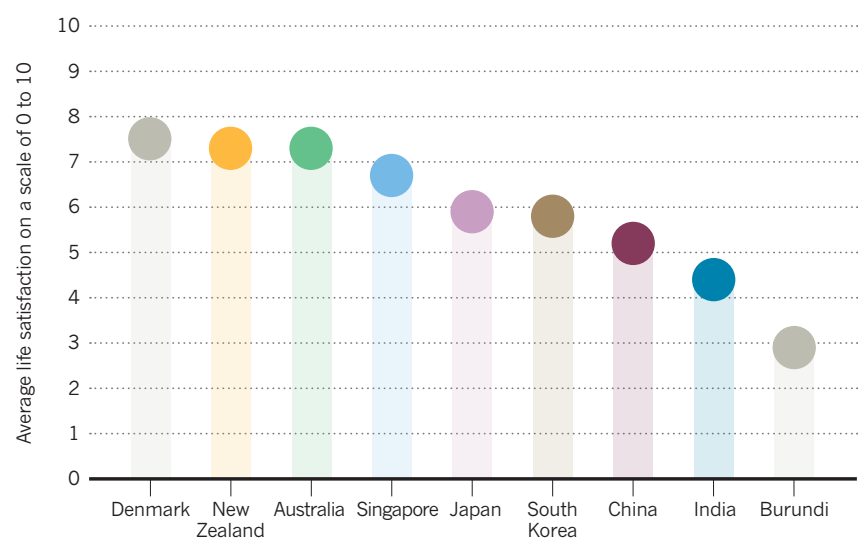

